\title{
Shrinkage of Hong Kong granite aggregate concrete
}

\author{
A. K. H. Kwan, F. T. K. Au, H. H. C. Wong and P. L. Ng \\ University of Hong Kong
}

In the design of many concrete structures, it is important to assess the amount of shrinkage that could occur because shrinkage could lead to extensive cracking or substantial prestress loss. A number of shrinkage models have been developed all over the world but they differ widely from each other, indicating that the shrinkage of concrete is dependent on the characteristics of the materials used and the local conditions. Early experimental studies in Hong Kong suggested that the shrinkage of Hong Kong concrete is considerably larger than that estimated using shrinkage models developed elsewhere. This is probably due to the local granite aggregate used. In order to resolve this problem and develop a shrinkage model for Hong Kong, a comprehensive testing programme using fibre-optic strain gauges to measure the shrinkage strain was launched. The shrinkage measurement lasted over 3.5 years and covered concrete mixes with and without pulverised fuel ash added and with paste volume varying from 30 to $40 \%$.

\section{Introduction}

Shrinkage of reinforced concrete structures as the concrete dries after hardening is a natural phenomenon. It could lead to substantial shortening movement and, if the movement is restrained, serious cracking. The first two authors have been serving as independent consultants for some considerable time and have found that this is a common scene in Hong Kong, especially in podiums and car parks structurally connected to two or more core walls. In many cases, the shrinkage cracks formed have been causing aesthetic, water leakage and durability problems. Apart from cracking, shrinkage also causes prestress losses in prestressed concrete structures. As a result, the prestressing tendons have to be overstressed to allow for later prestress losses, thereby leading to significant increase in cost. To overcome these problems, it is necessary first of all to predict as accurately as possible the actual shrinkage strain of the concrete.

However, in Hong Kong, shrinkage measurement of concrete is not a common test and there have been few published data on the shrinkage of the local concrete.

Department of Civil Engineering, The University of Hong Kong, Pokfulam Road, Hong Kong, China

(MACR 800157) Paper received 10 September 2008; last revised 19 April; accepted 11 May 2009
Nevertheless, judging from the limited data available (Chai, 1980; City University of Hong Kong, 1995; China Light and Power, 1998), it may be estimated that the ultimate shrinkage of the local concrete is of the order of 600 to $1000 \mu \varepsilon$ (note: $1 \mu \varepsilon=1 \times 10^{-6}$ ), which on average is substantially larger than the predicted values by BS 5400 (BSI, 1990), Model Code 1990 (MC-90) (CEB, 1993), ACI-209 (ACI, 1997) or Eurocode 2 (BSI, 2004). In fact, the shrinkage models contained in these codes consider different factors and differ widely from each other. One major reason for the large discrepancy between the shrinkage models is their ignorance of the type of aggregate used, which varies from place to place and has great influence on the shrinkage of concrete (Neville, 1995; Alexander and Mindess, 2005). Hence, a shrinkage model developed from testing of concrete made with a particular type of aggregate is applicable only to concrete made with the same type of aggregate and shrinkage models developed elsewhere are not necessarily applicable in Hong Kong.

In Hong Kong, two types of aggregate, namely, volcanic and granite aggregates are used (Kwan et al., 1995). Experience indicates that concrete made with the volcanic aggregate has smaller shrinkage. Nevertheless, the granite aggregate is more commonly used because of its lower potential risk of alkali-aggregate reaction. For the volcanic aggregate concrete, there is no acceptable method of shrinkage prediction and the 
shrinkage has to be estimated by shrinkage tests. For the granite aggregate concrete, the usual practice is to follow the shrinkage model given in BS 5400 and multiply the estimated shrinkage by a factor $C_{\mathrm{s}}$ to allow for the larger anticipated shrinkage, as stipulated in the Structures Design Manual published by the Hong Kong government (Highways Department, 2006). In the early editions of the manual, the factor $C_{\mathrm{s}}$ was set equal to 4.0 while in the 2006 edition, the factor $C_{\mathrm{s}}$ was set equal to $3 \cdot 0$. These high values for $C_{\mathrm{s}}$ imply that the shrinkage of Hong Kong granite aggregate concrete is three to four times that of similar concrete in the UK. For many years, such implication has raised the question of whether the shrinkage of Hong Kong concrete is really that large and whether a new shrinkage model should be developed based on shrinkage tests carried out locally.

Literature search has identified hundreds of papers published on the shrinkage of concrete (Pickett, 1956; Troxell et al., 1958; Campbell-Allen and Holford, 1970; Bazant et al., 1987a, 1987b; Hansen and Almudaiheem, 1987; Bloom and Bentur, 1995; Bissonnette et al., 1999; Ayano and Wittmann, 2002; Barr et al., 2003). However, despite extensive studies by many researchers, the mechanism of concrete shrinkage is not yet fully understood. This is reflected also in the large differences between the codified shrinkage models (ACI, 1997; BSI, 1990, 2004; CEB, 1993). Nevertheless, it is now clear that the major factors affecting concrete shrinkage include at least the aggregate properties, aggregate content, water content, cementitious materials, curing conditions, environmental conditions and member size and shape. Among these factors, the aggregate properties, curing conditions and environmental conditions are local factors because they are dependent on where the concrete is produced. Hence, unless the local factors are properly accounted for, it is difficult to develop an appropriate shrinkage model. In fact, the local granite rock has been found to have relatively high water absorption and relatively low elastic modulus (Lee et al., 2000). These properties of the local granite rock are likely to be the main contributing factors to the large shrinkage of Hong Kong concrete. The present authors are currently investigating the effects of aggregate properties on concrete shrinkage (Kwan and Wong, 2007), but since it takes time for completion, this investigation would not provide a quick solution.

In view of the above situation, the industry has requested shrinkage tests to be carried out so as to develop a shrinkage model for Hong Kong. In response, the authors launched a comprehensive shrinkage testing programme in 2003, as reported herein. A total of 72 concrete specimens were tested up to 3.5 years of drying. For measurement stability, fibre-optic strain gauges were used to measure the shrinkage strains. From the test results, the effects of pulverised fuel ash, paste volume, concrete grade and humidity are studied and a shrinkage model is developed.

\section{Existing codified shrinkage models}

In this section, the shrinkage models in British Standard BS 5400: Part 4: 1990 (BSI, 1990), CEB-FIP Model Code 1990 (CEB, 1993), ACI Committee 209 Report (ACI, 1997) and Eurocode 2: Part 1-1 (BSI, 2004) are reviewed and compared with each other.

\section{British Standard BS 5400: Part 4: 1990 (BS 5400)}

According to BS 5400, the shrinkage strain $\varepsilon_{\mathrm{sh}}(t)$ at time $t$ after end of curing can be evaluated as the product of four partial coefficients, as given by

$$
\varepsilon_{\mathrm{sh}}(t)=K_{L} K_{\mathrm{c}} K_{\mathrm{e}} K_{j}
$$

where $K_{L}$ depends on the relative humidity, $K_{\mathrm{c}}$ depends on the composition of the concrete, $K_{\mathrm{e}}$ depends on the effective thickness of the member, and $K_{j}$ defines the development of shrinkage with time $t$. The coefficients $K_{L}, K_{\mathrm{c}}, K_{\mathrm{e}}$ and $K_{j}$ are presented in the form of charts. From the chart for $K_{L}$, it can be determined that at relative humidity $(\mathrm{RH})$ levels of $90 \%, 70 \%$ and $50 \%$, the values of $K_{L}$ are 115,275 and $380 \mu \varepsilon$, respectively. From the chart for $K_{\mathrm{c}}$, it can be seen that $K_{\mathrm{c}}$ increases with both the cement content and the water/cement ratio, and generally ranges from 0.75 to $1 \cdot 50$. From the chart for $K_{\mathrm{e}}$, the corresponding values of $K_{\mathrm{e}}$ at effective thickness of $100 \mathrm{~mm}, 200 \mathrm{~mm}, 300 \mathrm{~mm}$ and $400 \mathrm{~mm}$ may be obtained as $1 \cdot 02,0 \cdot 80,0.65$ and 0.55 , respectively. From the chart for $K_{j}$, it can be seen that the shrinkage half-time varies from 20 days at an effective thickness of $50 \mathrm{~mm}$ to 400 days at an effective thickness of $400 \mathrm{~mm}$.

\section{CEB-FIP Model Code 1990 (MC-90)}

In MC-90, the shrinkage $\varepsilon_{\mathrm{sh}}(t)$ at time $t$ after end of curing is evaluated in terms of the ultimate shrinkage $\left(\varepsilon_{\mathrm{sh}}\right)_{\mathrm{u}}$ and the time function $\beta_{\mathrm{s}}(t)$ as

$$
\varepsilon_{\mathrm{sh}}(t)=\left(\varepsilon_{\mathrm{sh}}\right)_{\mathrm{u}} \cdot \beta_{\mathrm{s}}(t)
$$

For the ultimate shrinkage $\left(\varepsilon_{\mathrm{sh}}\right)_{\mathrm{u}}$, the following formula is provided

$$
\left(\varepsilon_{\mathrm{sh}}\right)_{\mathrm{u}}=\varepsilon_{\mathrm{s}}\left(f_{\mathrm{cm}}\right) \beta_{\mathrm{RH}}
$$

where the coefficients $\varepsilon_{\mathrm{s}}\left(f_{\mathrm{cm}}\right)$ and $\beta_{\mathrm{RH}}$ are given by

$$
\begin{gathered}
\varepsilon_{\mathrm{s}}\left(f_{\mathrm{cm}}\right)=\left[160+10 \beta_{\mathrm{sc}}\left(9-f_{\mathrm{cm}} / 10\right)\right] \times 10^{-6} \\
\beta_{\mathrm{RH}}=1.55 \times\left[1-(\mathrm{RH} / 100)^{3}\right]
\end{gathered}
$$

In the above, $\beta_{\mathrm{sc}}$ is equal to 4,5 and 8 for slow-hardening cements, normal or rapidly hardening cements, and rapidly hardening high-strength cements, respectively; $f_{\mathrm{cm}}$ is the mean cylinder strength of the concrete $(\mathrm{MPa}) ; \mathrm{RH}$ is the relative humidity (\%). The time function $\beta_{\mathrm{s}}(t)$ is given by

$$
\beta_{\mathrm{s}}(t)=\left[\frac{t}{350\left(h / h_{0}\right)^{2}+t}\right]^{0.5}
$$


in which $h$ is the effective thickness of the concrete member, $h_{0}$ is a reference thickness taken as $100 \mathrm{~mm}$ and $t$ is the time in days.

\section{ACI Committee 209 Report (ACI-209)}

According to ACI-209, the shrinkage $\varepsilon_{\mathrm{sh}}(t)$ may be evaluated as a product of $\left(\varepsilon_{\mathrm{sh}}\right)_{\mathrm{u}}$ and $\beta_{\mathrm{s}}(t)$. The ultimate shrinkage $\left(\varepsilon_{\mathrm{sh}}\right)_{\mathrm{u}}$ is given by

$$
\left(\varepsilon_{\mathrm{sh}}\right)_{\mathrm{u}}=780 \times 10^{-6} \gamma_{\mathrm{sh}}
$$

in which $\gamma_{\text {sh }}$ is a modification factor taken as the product of several multipliers

$$
\gamma_{\mathrm{sh}}=\gamma_{\mathrm{rh}} \cdot \gamma_{\mathrm{s}} \cdot \gamma_{\mathrm{fa}} \cdot \gamma_{\mathrm{cc}} \cdot \gamma_{\alpha} \cdot \gamma_{\mathrm{thk}}
$$

The multipliers $\gamma_{\mathrm{rh}}, \gamma_{\mathrm{s}}, \gamma_{\mathrm{fa}}, \gamma_{\mathrm{cc}}, \gamma_{\mathrm{a}}$ and $\gamma_{\text {thk }}$ are to allow for the effects of relative humidity, slump, fine to total aggregate ratio, cement content, air content and effective thickness, respectively. On the other hand, the time function $\beta_{\mathrm{s}}(t)$ is given by

$$
\beta_{\mathrm{s}}(t)=\left[\frac{t}{35+t}\right]
$$

\section{Eurocode 2: Part 1-1 (Eurocode 2)}

In Eurocode 2, the shrinkage $\varepsilon_{\mathrm{sh}}(t)$ is also evaluated as a product of $\left(\varepsilon_{\mathrm{sh}}\right)_{\mathrm{u}}$ and $\beta_{\mathrm{s}}(t)$. For the ultimate shrinkage $\left(\varepsilon_{\mathrm{sh}}\right)_{\mathrm{u}}$, the following formula is provided

$$
\left(\varepsilon_{\mathrm{sh}}\right)_{\mathrm{u}}=k_{\mathrm{h}} \cdot \varepsilon_{\mathrm{s}}\left(f_{\mathrm{cm}}\right) \cdot \beta_{\mathrm{RH}}
$$

in which $k_{h}$ is a coefficient depending on the effective thickness $h$ to allow for the size effect, and the coefficients $\varepsilon_{\mathrm{s}}\left(f_{\mathrm{cm}}\right)$ and $\beta_{\mathrm{RH}}$ are given by

$$
\begin{aligned}
\varepsilon_{\mathrm{s}}\left(f_{\mathrm{cm}}\right)= & 0.85 \times\left[\left(220+110 \alpha_{\mathrm{ds} 1}\right) \cdot \exp \left(-\alpha_{\mathrm{ds} 2} f_{\mathrm{cm}} / 10\right)\right] \\
& \times 10^{-6} \\
& \beta_{\mathrm{RH}}=1.55 \times\left[1-(\mathrm{RH} / 100)^{3}\right]
\end{aligned}
$$

In the above, $\alpha_{\mathrm{ds} 1}$ is equal to 3, 4 and 6 for cement of class $\mathrm{S}, \mathrm{N}$ and $\mathrm{R}$, respectively, $\alpha_{\mathrm{ds} 2}$ is equal to $0 \cdot 13$, $0 \cdot 12$ and 0.11 for cement of class $\mathrm{S}, \mathrm{N}$ and $\mathrm{R}$, respectively, $f_{\mathrm{cm}}$ is the mean cylinder strength of the concrete (MPa) and $\mathrm{RH}$ is the relative humidity (\%). On the other hand, the time function $\beta_{\mathrm{s}}(t)$ is given by

$$
\beta_{\mathrm{s}}(t)=\left[\frac{t}{0 \cdot 04 \sqrt{h^{3}}+t}\right]
$$

\section{Comparison of existing codified shrinkage models}

From the above, it can be seen that the existing shrinkage models do not quite agree with each other. For the same concrete, the predicted ultimate shrinkage strains by the four codified shrinkage models could differ from each other by up to $50 \%$. The discrepancies in the predicted shrinkage half-time are even larger. In BS 5400, the shrinkage half-time ranges from 22 days at an effective thickness of $50 \mathrm{~mm}$ to 400 days at an effective thickness of $400 \mathrm{~mm}$. In MC-90, the shrinkage half-time ranges from 29 days at an effective thickness of $50 \mathrm{~mm}$ to 1867 days at an effective thickness of $400 \mathrm{~mm}$. In ACI-209, the shrinkage half-time is always equal to 35 days, regardless of the effective thickness. In Eurocode 2, the shrinkage half-time ranges from 14 days at an effective thickness of $50 \mathrm{~mm}$ to 320 days at an effective thickness of $400 \mathrm{~mm}$. Nevertheless, the four codified shrinkage models have one feature in common: they all ignore the possible effects of the properties of the aggregate used.

It is not easy to judge which shrinkage model is better than the others. Herein, the selection of the shrinkage model to be adopted in Hong Kong would be based on how good the predicted ultimate shrinkage strains and shrinkage half-times agree with the test results obtained from the shrinkage testing programme. However, as will be shown later, as none of the above shrinkage models agree well with the test results, the selected shrinkage model has to be modified for application in Hong Kong.

\section{Shrinkage testing programme}

As the shrinkage of concrete could continue for a long time, it is important to choose a strain measurement device that is stable up to at least several years. Both electronic and fibre-optic strain gauges have been considered for measuring the shrinkage strains. Because of their higher stability and accuracy, fibre-optic strain gauges were chosen. The fibre-optic strain gauges used are of an embedded type, as shown in Figure 1. Details of these strain gauges can be found from the website www.fiso.com. They are based on Fabry-Perot optical technology (Quirion and Ballivy, 2000) and their measurement range, resolution and accuracy are $\pm 2000 \mu \varepsilon, 0 \cdot 2 \mu \varepsilon$ and $0 \cdot 5 \mu \varepsilon$ respectively. They were mounted into the moulds of the specimens before casting.

The concrete specimens were prismatic and of size $75 \mathrm{~mm} \times 75 \mathrm{~mm} \times 250 \mathrm{~mm}$, as shown in Figure 2 . Steel moulds were used for casting the specimens. Immediately after casting, the trowelled surfaces of the specimens were covered with plastic sheets so that all surfaces of the specimens were protected from drying. At $24 \mathrm{~h}$ after casting, the specimens were demoulded and then cured by covering the whole lot of specimens with wet hessian until the age of 7 days. After the curing period, each concrete specimen was coated at the two end surfaces and the top and bottom surfaces with an impermeable polymer latex impregnated cementitious mortar so that only the two side surfaces would be subjected to drying. With only the two side surfaces subjected to drying, the effective thickness of each specimen is the same as the breadth of the specimen, that is $75 \mathrm{~mm}$.

After coating, the specimens were placed inside two 


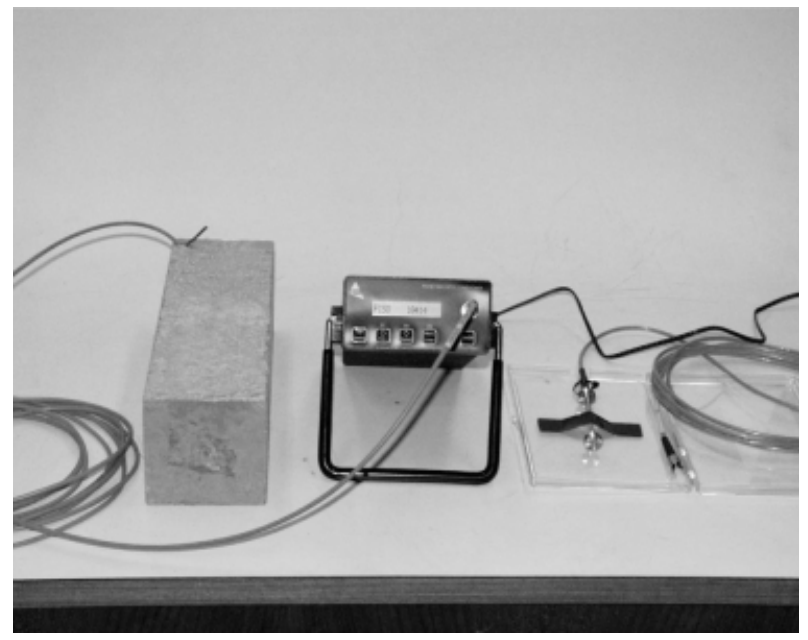

Figure 1. Fibre-optic strain measurement system

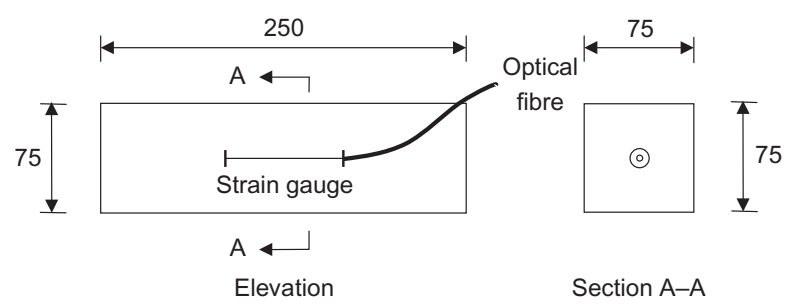

(a)

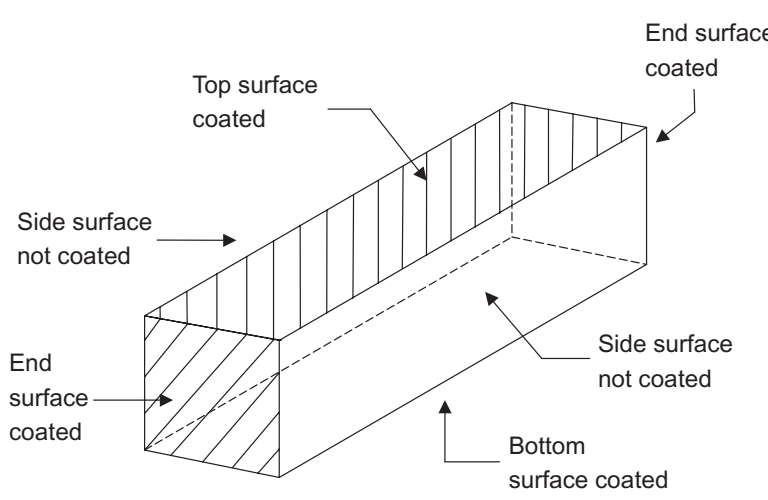

(b)

Figure 2. Shrinkage test specimen: (a) dimensions of specimen and location of strain gauge; (b) coating of surfaces

condition chambers, each controlled at the required temperature and relative humidity $(\mathrm{RH})$, for the drying shrinkage tests. One chamber was maintained at $27^{\circ} \mathrm{C}$ and $75 \% \mathrm{RH}$, while the other chamber was maintained at $27^{\circ} \mathrm{C}$ and $50 \% \mathrm{RH}$. The temperature and humidity inside each chamber were continuously monitored and the results verified that in each chamber, the temperature was controlled at within $\pm 2^{\circ} \mathrm{C}$ of the required temperature and the $\mathrm{RH}$ was controlled at within $\pm 5 \%$ of the required $\mathrm{RH}$ throughout the entire testing period. During the first month, the shrinkage strains were measured daily and thereafter, as the shrinkage slowed down, at successively reduced frequency.

All the concrete mixes were produced using only locally available materials. Particularly, the local granite aggregate was used throughout and thus the test results are applicable to concrete mixes made with the local granite aggregate. A total of 18 concrete mixes were cast for testing. They were of grade 35 to 45 (the grade is defined as the characteristic 28-day cube compressive strength in $\mathrm{MPa}$ ), with a target slump of $100 \mathrm{~mm}$, with and without pulverised fuel ash (PFA) added and with paste volume varying from 30 to $40 \%$. They were designed based on the data of typical concrete mixes in Hong Kong provided by the local government. The basic mix data and mix proportions of the concrete mixes are presented in Tables 1 and 2 respectively.

The 18 concrete mixes may be divided into three groups. In the first, second and third groups, the paste volumes of the concrete mixes were set at $30 \%, 35 \%$ and $40 \%$ respectively. Apart from the difference in paste volume, the six concrete mixes in each group have the same paste compositions as the respective concrete mixes in the other groups. Basically, in each group, the first concrete mix (mix 1, 7 or 13) is of grade 35 and contains $25 \%$ PFA, the second concrete mix (mix 2, 8 or 14) is of grade 35 and contains no PFA, the third concrete mix (mix 3, 9 or 15) is of grade 40 and contains $25 \%$ PFA, the fourth concrete mix (mix 4,10 or 16 ) is of grade 40 and contains no PFA, the fifth concrete mix (mix 5, 11 or 17) is of grade 45 and contains $25 \%$ PFA and the sixth concrete mix (mix 6,12 or 18) is of grade 45 and contains no PFA. In each concrete mix, a workability admixture was added such that the measured slump was approximately $100 \mathrm{~mm}$.

Each concrete mix was tested under two humidity conditions: (a) $\mathrm{RH}=75 \%$ (the yearly average $\mathrm{RH}$ in Hong Kong); and (b) $\mathrm{RH}=50 \%$. For each concrete mix and each humidity condition, the shrinkage tests were carried out in duplicates with two identical specimens cast at the same time and tested side by side so that the validity of the test results could be verified by cross checking. Therefore, from each concrete mix, four prismatic specimens were cast for shrinkage tests. In addition, from each concrete mix, six $150 \mathrm{~mm}$ cube specimens were cast for cube compression tests at the ages of 7 days and 28 days. Altogether, 72 prismatic specimens and 108 cube specimens were cast for testing. Overall, the shrinkage testing programme lasted over four years with at least $3 \cdot 5$ years of shrinkage test results obtained for each concrete mix.

\section{Test results}

The strength and workability results of the concrete mixes are presented in Table 3. From these results, it 
Table 1. Basic mix data

\begin{tabular}{|c|c|c|c|c|c|c|}
\hline Mix no. & Grade: $\mathrm{MPa}$ & Paste volume: \% & Target slump: mm & $\begin{array}{l}\text { W/B ratio } \\
(\text { Note } 1)\end{array}$ & $\begin{array}{c}\text { PFA dosage } \\
\text { (Note } 2 \text { ) }\end{array}$ & $\begin{array}{c}\text { Fine to total } \\
\text { aggregate ratio }\end{array}$ \\
\hline $\begin{array}{l}1 \\
2 \\
3 \\
4 \\
5 \\
6 \\
7 \\
8 \\
9 \\
10 \\
11 \\
12 \\
13 \\
14 \\
15 \\
16 \\
17 \\
18\end{array}$ & $\begin{array}{l}35 \\
35 \\
40 \\
40 \\
45 \\
45 \\
35 \\
35 \\
40 \\
40 \\
45 \\
45 \\
35 \\
35 \\
40 \\
40 \\
45 \\
45\end{array}$ & $\begin{array}{l}30 \\
\\
35 \\
\\
\\
40\end{array}$ & $\begin{array}{l}100 \\
100 \\
\\
100\end{array}$ & $\begin{array}{l}0 \cdot 45 \\
0 \cdot 48 \\
0 \cdot 42 \\
0 \cdot 44 \\
0 \cdot 39 \\
0 \cdot 41 \\
0 \cdot 45 \\
0 \cdot 48 \\
0 \cdot 42 \\
0 \cdot 44 \\
0 \cdot 39 \\
0 \cdot 41 \\
0 \cdot 45 \\
0 \cdot 48 \\
0 \cdot 42 \\
0 \cdot 44 \\
0 \cdot 39 \\
0.41\end{array}$ & $\begin{array}{l}0 \cdot 25 \\
0 \cdot 00 \\
0 \cdot 25 \\
0 \cdot 00 \\
0 \cdot 25 \\
0 \cdot 00 \\
0 \cdot 25 \\
0 \cdot 00 \\
0 \cdot 25 \\
0 \cdot 00 \\
0 \cdot 25 \\
0 \cdot 00 \\
0 \cdot 25 \\
0 \cdot 00 \\
0 \cdot 25 \\
0 \cdot 00 \\
0 \cdot 25 \\
0 \cdot 00\end{array}$ & $0 \cdot 38$ \\
\hline
\end{tabular}

Notes

1. W/B ratio means water/binder ratio by weight; binder includes OPC (ordinary Portland cement) and PFA (pulverised fuel ash).

2. PFA dosage is expressed in terms of ratio of total binder content by weight.

Table 2. Mix proportions

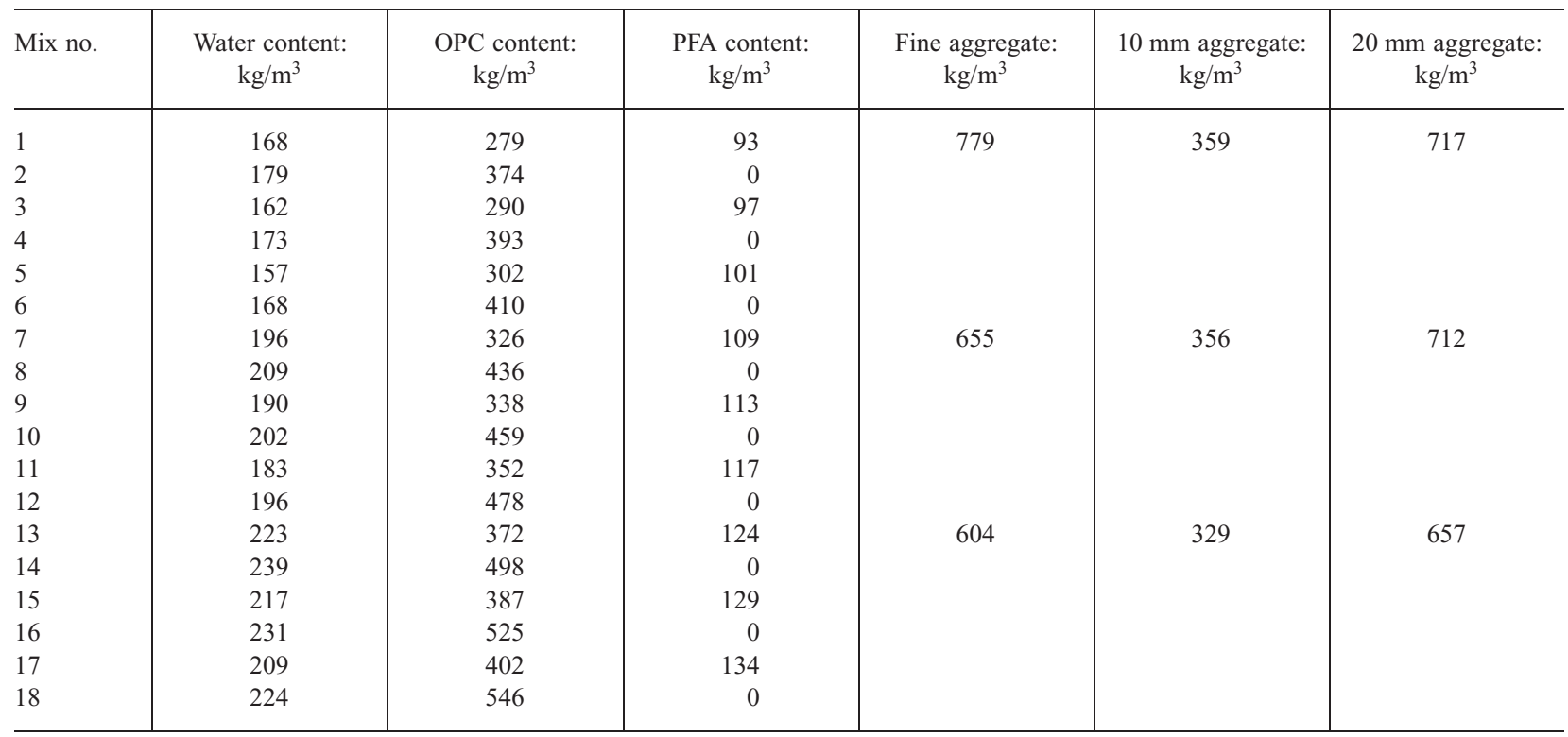

can be seen that the mean 28 day cube strengths of the various concrete mixes were each higher than the respective specified grade by a generous margin (this is a common practice in Hong Kong). On the other hand, the measured slump values were all within 65 to $100 \mathrm{~mm}$.

To illustrate the development of shrinkage with time, the shrinkage-time curves of some concrete mixes at $\mathrm{RH}=75 \%$ and $\mathrm{RH}=50 \%$ are plotted in Figures 3 and 4 respectively. In each graph, the two shrinkage-time curves of the duplicated specimens cast from the same concrete and tested under the same conditions are plotted together. It is noteworthy that the two curves differ slightly, indicating that although the duplicated specimens are supposed to be identical, their shrinkage strains are not exactly the same. Nevertheless, the difference in shrinkage strain is, in all cases, less than $15 \%$. Bearing in mind that the shrinkage of concrete is quite erratic, such variations in the measured shrinkage strains are regarded as acceptable. Among the 36 pairs of duplicated specimens, five pairs have in each pair only one specimen tested to the end owing to damage of the optical fibres (the optical fibres connecting the strain gauges to the readout unit were very fragile). In 
Table 3. Strength and workability results

\begin{tabular}{|c|c|c|c|c|}
\hline Mix no. & Grade: MPa & $\begin{array}{c}\text { Mean 7-day cube strength: } \\
\text { MPa }\end{array}$ & $\begin{array}{c}\text { Mean 28-day cube strength: } \\
\text { MPa }\end{array}$ & Slump: mm \\
\hline 1 & 35 & $36 \cdot 2$ & 51.7 & 85 \\
\hline 2 & 35 & 44.5 & $55 \cdot 0$ & 100 \\
\hline 3 & 40 & $39 \cdot 2$ & $56 \cdot 2$ & 95 \\
\hline 4 & 40 & $51 \cdot 8$ & $61 \cdot 0$ & 75 \\
\hline 5 & 45 & $50 \cdot 4$ & $66 \cdot 0$ & 80 \\
\hline 6 & 45 & $51 \cdot 4$ & $62 \cdot 0$ & 90 \\
\hline 7 & 35 & $35 \cdot 1$ & $49 \cdot 0$ & 75 \\
\hline 8 & 35 & $44 \cdot 1$ & $52 \cdot 6$ & 95 \\
\hline 9 & 40 & $39 \cdot 4$ & $54 \cdot 7$ & 80 \\
\hline 10 & 40 & $52 \cdot 6$ & $62 \cdot 4$ & 75 \\
\hline 11 & 45 & $45 \cdot 9$ & $63 \cdot 0$ & 75 \\
\hline 12 & 45 & $54 \cdot 3$ & $64 \cdot 7$ & 65 \\
\hline 13 & 35 & $33 \cdot 3$ & $46 \cdot 6$ & 90 \\
\hline 14 & 35 & $42 \cdot 0$ & $51 \cdot 2$ & 80 \\
\hline 15 & 40 & $38 \cdot 6$ & $54 \cdot 6$ & 85 \\
\hline 16 & 40 & $47 \cdot 7$ & $58 \cdot 3$ & 90 \\
\hline 17 & 45 & 44.9 & $61 \cdot 4$ & 85 \\
\hline 18 & 45 & $52 \cdot 9$ & $62 \cdot 2$ & 75 \\
\hline
\end{tabular}

Note: Each cube strength result is the mean of three cubes cast from the same concrete and tested at the same time.

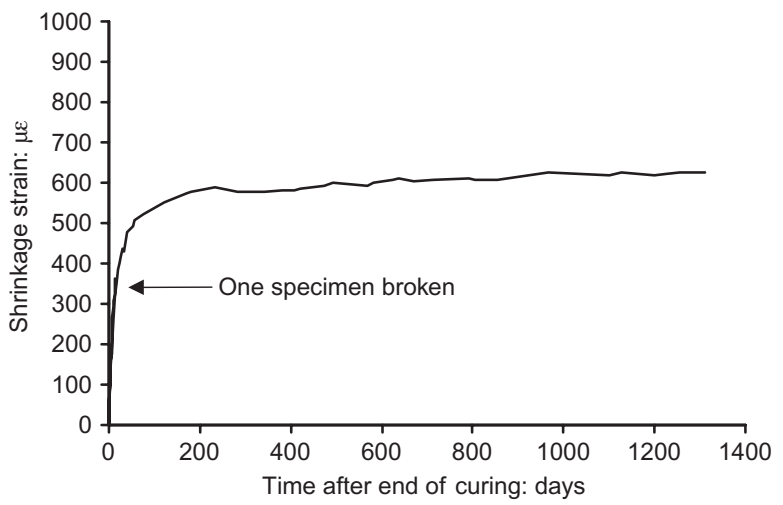

(a)

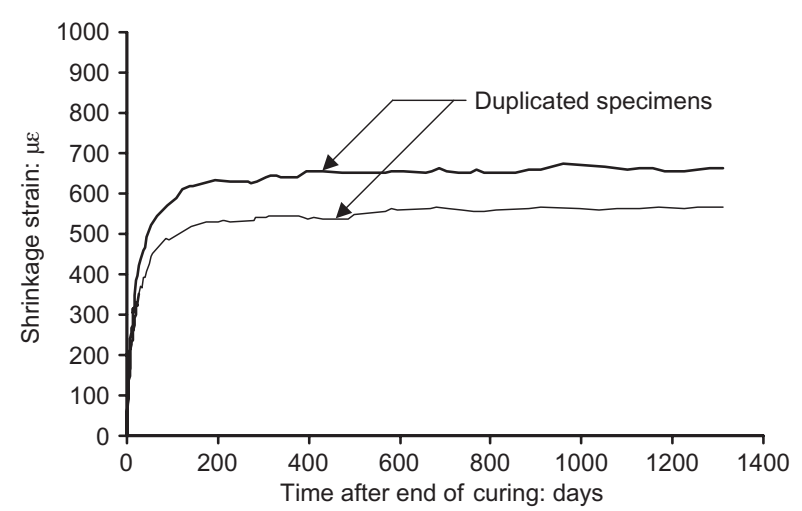

(b)

Figure 3. Shrinkage-time curves of some concrete mixes at $R H=75 \%$ : (a) mix 1; (b) $\operatorname{mix} 2$

such cases, although no cross checking of the test results is possible, the test results of the remaining specimens are still regarded as valid.

From the shrinkage-time curves, it can be seen that,

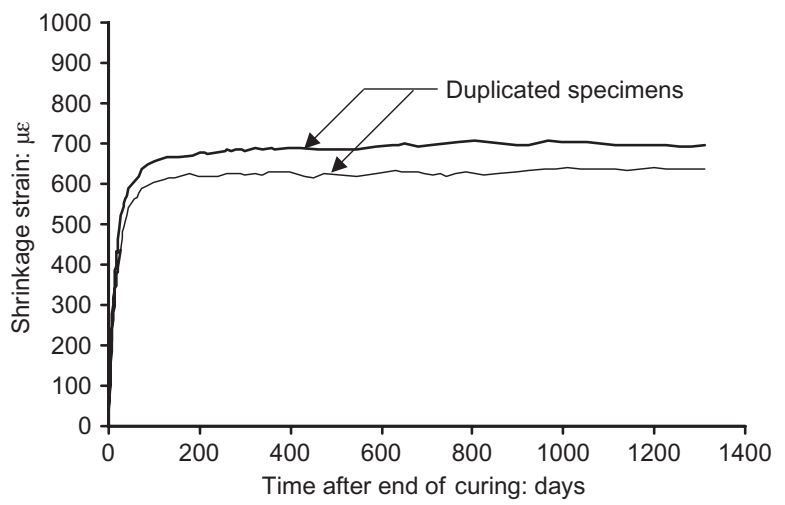

(a)

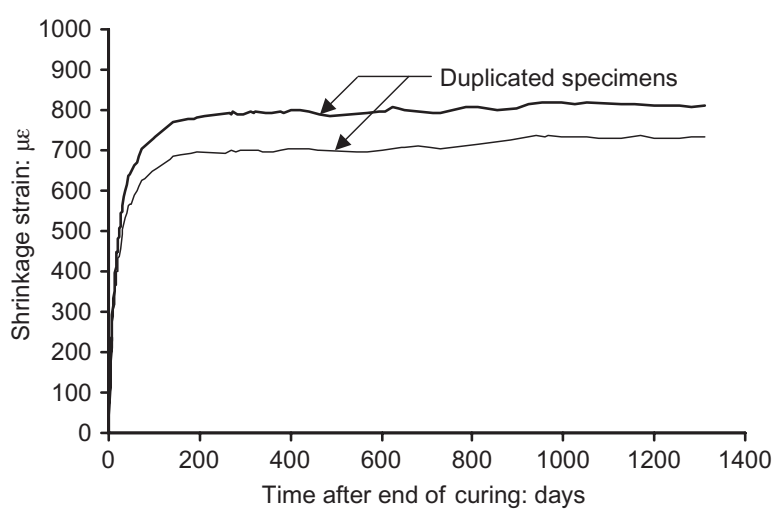

(b)

Figure 4. Shrinkage-time curves of some concrete mixes at RH $=50 \%$ : (a) $\operatorname{mix} 1$; (b) $\operatorname{mix} 2$

in general, the shrinkage increased with time initially at a rapid rate and then at a gradually decreasing rate until after about one year, the shrinkage increased only marginally with time. From each shrinkage-time curve, the 
ultimate shrinkage is determined as the shrinkage strain at the end of the shrinkage test (at least 3.5 years after end of curing) and the shrinkage half-time is determined as the time taken for the shrinkage to reach half of the ultimate shrinkage. As the duplicated specimens yield slightly different results, the ultimate shrinkage and shrinkage half-time of a concrete mix tested under certain specific conditions are taken as the average ultimate shrinkage and average shrinkage half-time of the duplicated specimens (or if one specimen has failed, those of the remaining specimen). The ultimate shrinkage and shrinkage half-time results so obtained are summarised in Table 4. From these results, it is evident that for the concrete mixes tested, the ultimate shrinkage ranges approximately from 540 to $800 \mu \varepsilon$, while the shrinkage half-time ranges approximately from 8 to 20 days.

To study the effects of PFA, the concrete mixes were designed in nine pairs such that the two mixes in each pair are of the same concrete grade and have the same paste volume but one mix contains PFA whereas the other mix contains no PFA. The nine pairs are: (mix 1 and 2), (mix 3 and 4), (mix 5 and 6), (mix 7 and 8), (mix 9 and 10), (mix 11 and 12), (mix 13 and 14), (mix 15 and 16) and (mix 17 and 18). In Figure 5, the ultimate shrinkage and shrinkage half-time of the concrete mixes containing PFA are compared with the corresponding ultimate shrinkage and shrinkage half-time of similar concrete mixes containing no PFA. From this figure, it can be seen that the use of PFA has no obvious effect on the ultimate shrinkage but a certain effect on the shrinkage half-time. On average, for the same curing period of 7 days, the use of PFA shortens the shrinkage half-time by about $20 \%$.

To study the effects of paste volume, the concrete mixes were designed in six sets each comprising three mixes such that the three mixes in each set have the same paste composition but different paste volumes of $30 \%, 35 \%$ and $40 \%$. The six sets are: (mix 1, 7 and 13), (mix 2, 8 and 14), (mix 3, 9 and 15), (mix 4, 10 and 16), (mix 5, 11 and 17) and (mix 6, 12 and 18). In Figure 6 , the ultimate shrinkage and shrinkage halftime of the concrete mixes are plotted against the paste volume. From this figure, it is evident that as the paste volume increases from $30 \%$ to $35 \%$, the ultimate shrinkage increases significantly while the shrinkage half-time decreases significantly. However, as the paste volume further increases from $35 \%$ to $40 \%$, both the ultimate shrinkage and shrinkage half-time remain more or less the same.

To study the effects of concrete grade, the ultimate shrinkage and shrinkage half-time of the concrete mixes are plotted against the 28-day cube strength in Figure 7. From the curves plotted in the figure, it can be seen that the ultimate shrinkage decreases significantly as the concrete strength increases but the shrinkage half-time appears to be insensitive to the concrete strength.

To study the effects of RH, the ultimate shrinkage and shrinkage half-time of the specimens tested at $\mathrm{RH}=50 \%$ are compared with those of the specimens tested at $\mathrm{RH}=75 \%$ in Figure 8 . The comparison reveals that at $\mathrm{RH}=50 \%$, the ultimate shrinkage is about $11 \%$ larger and the shrinkage half-time is about $10 \%$ shorter than those at $\mathrm{RH}=75 \%$.

Table 4. Shrinkage test results

\begin{tabular}{|c|c|c|c|c|c|c|}
\hline \multirow[t]{2}{*}{ Mix no. } & \multirow[t]{2}{*}{ Grade: $\mathrm{MPa}$} & \multirow[t]{2}{*}{ Paste volume: \% } & \multicolumn{2}{|c|}{$\mathrm{RH}=75 \%$} & \multicolumn{2}{|c|}{$\mathrm{RH}=50 \%$} \\
\hline & & & $\begin{array}{l}\text { Ultimate shrinkage } \\
\text { strain: } \mu \varepsilon\end{array}$ & $\begin{array}{c}\text { Shrinkage half-time: } \\
\text { days }\end{array}$ & $\begin{array}{c}\text { Ultimate shrinkage } \\
\text { strain: } \mu \varepsilon\end{array}$ & $\begin{array}{c}\text { Shrinkage half-time: } \\
\text { days }\end{array}$ \\
\hline 1 & 35 & 30 & 627 & $13 \cdot 0$ & 668 & $12 \cdot 6$ \\
\hline 2 & 35 & & 616 & $15 \cdot 6$ & 771 & $14 \cdot 7$ \\
\hline 3 & 40 & & 591 & $12 \cdot 4$ & 680 & $10 \cdot 9$ \\
\hline 4 & 40 & & 588 & $11 \cdot 8$ & 696 & $10 \cdot 8$ \\
\hline 5 & 45 & & 551 & $20 \cdot 4$ & 654 & $13 \cdot 7$ \\
\hline 6 & 45 & & 543 & $19 \cdot 5$ & 656 & $16 \cdot 2$ \\
\hline 7 & 35 & 35 & 636 & $9 \cdot 6$ & 703 & $8 \cdot 3$ \\
\hline 8 & 35 & & 675 & $15 \cdot 5$ & 711 & $13 \cdot 4$ \\
\hline 9 & 40 & & 703 & $8 \cdot 2$ & 720 & $8 \cdot 6$ \\
\hline 10 & 40 & & 686 & $15 \cdot 2$ & 762 & $11 \cdot 3$ \\
\hline 11 & 45 & & 758 & $8 \cdot 0$ & 781 & $7 \cdot 4$ \\
\hline 12 & 45 & & 730 & $12 \cdot 7$ & 794 & $11 \cdot 6$ \\
\hline 13 & 35 & 40 & 778 & $9 \cdot 2$ & 722 & $8 \cdot 8$ \\
\hline 14 & 35 & & 668 & $15 \cdot 6$ & 746 & $15 \cdot 2$ \\
\hline 15 & 40 & & 636 & $10 \cdot 0$ & 745 & $8 \cdot 3$ \\
\hline 16 & 40 & & 652 & $13 \cdot 2$ & 660 & 11.7 \\
\hline 17 & 45 & & 674 & $8 \cdot 3$ & 787 & $7 \cdot 8$ \\
\hline 18 & 45 & & 624 & $10 \cdot 5$ & 718 & 9.9 \\
\hline
\end{tabular}



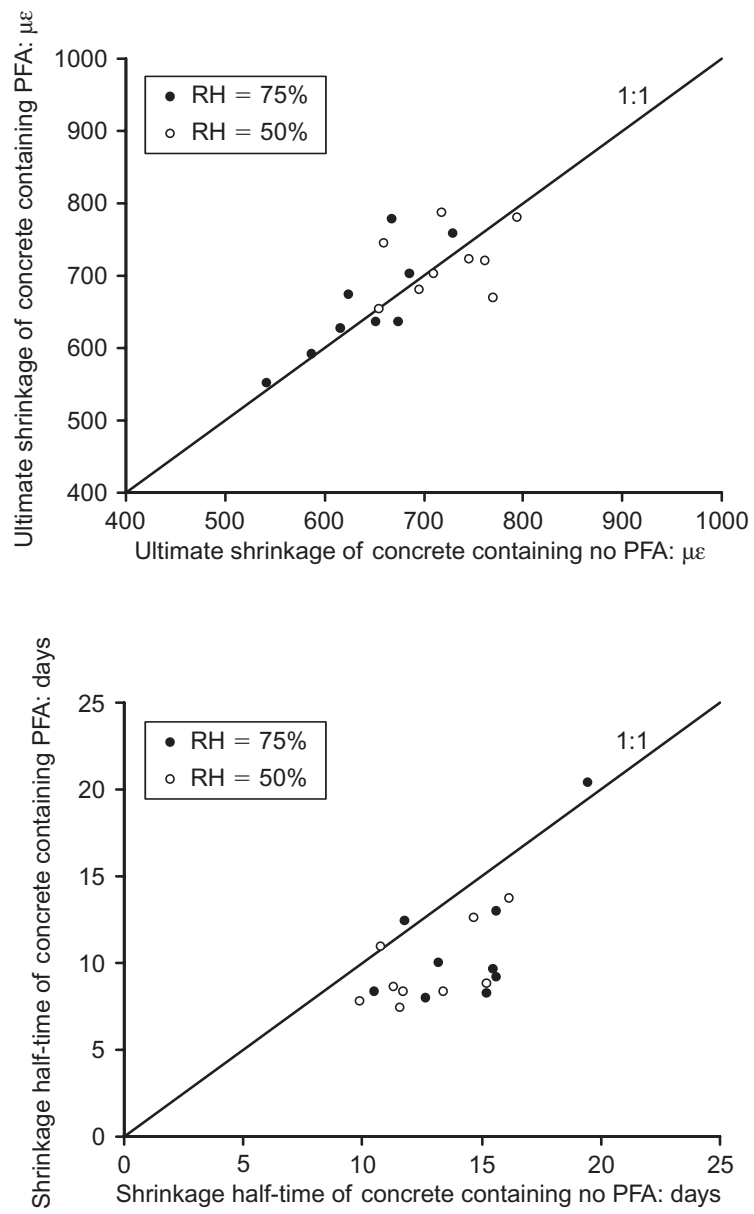

Figure 5. Effects of PFA on ultimate shrinkage and shrinkage half-time

All the shrinkage results presented above are those of drying shrinkage starting from the end of curing. The autogenous shrinkage, which occurred during the 7 days of curing, had also been measured and was found to be generally within 50 to $100 \mu \varepsilon$. However, no definite relationship between the autogenous shrinkage and the various concrete mix parameters could be found.

\section{Shrinkage model for Hong Kong concrete}

The measured shrinkage strains of the concrete mixes have been compared with the predicted values by BS 5400, MC-90, ACI-209 and Eurocode 2. However, none of the shrinkage models given in these four codes agrees well with the measured results. For illustration, the measured ultimate shrinkage strains are compared with the predicted ultimate shrinkage strains by BS 5400 and Eurocode 2 in Table 5.

From the comparison between the measured ultimate shrinkage strains and the predicted values by BS 5400, it can be seen that at $\mathrm{RH}=75 \%$, the measured ultimate shrinkage strains are on average equal to $2 \cdot 3$ times the predicted values and at $\mathrm{RH}=50 \%$, the measured ultimate shrinkage strains are on average equal to 1.7
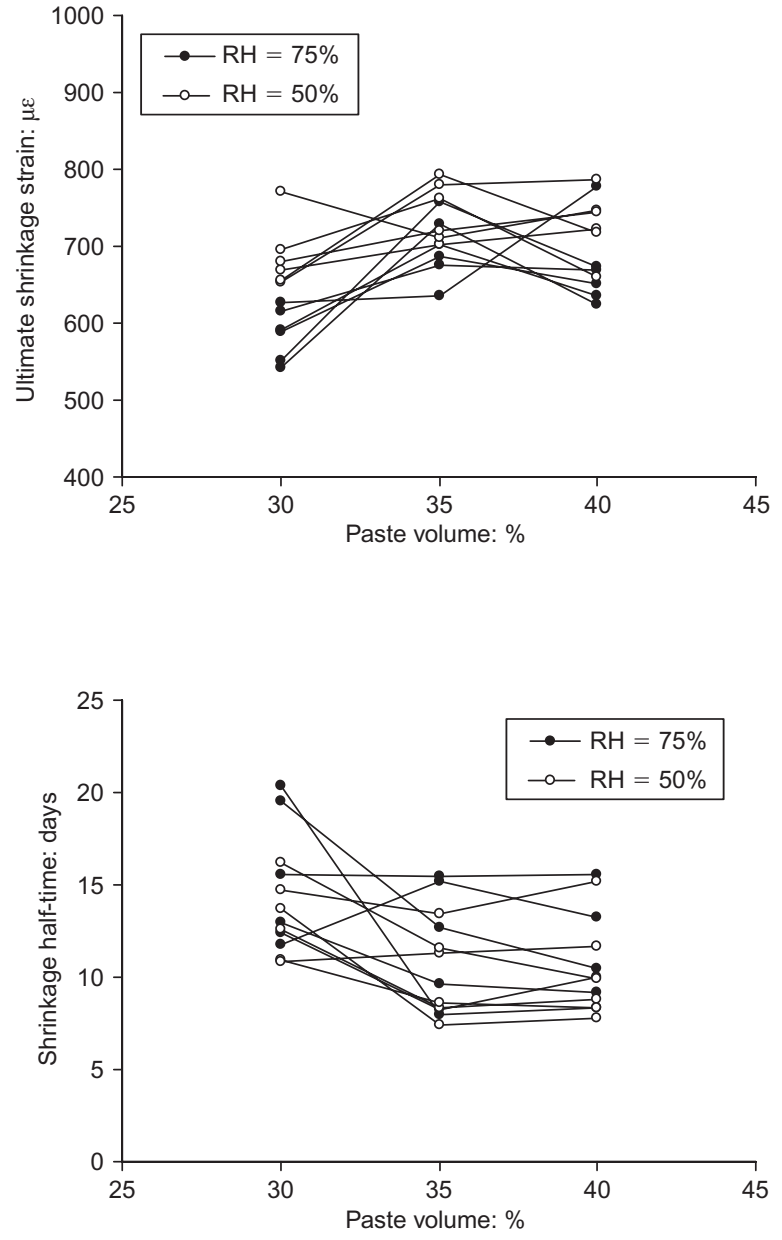

Figure 6. Effects of paste volume on ultimate shrinkage and shrinkage half-time

times the predicted values. Hence, the predicted ultimate shrinkage strains by BS 5400 are much too low to be realistic and the shrinkage model given in BS 5400 should not be directly applied in Hong Kong. On the other hand, however, the current practice of adopting the shrinkage model in BS 5400 and multiplying the predicted shrinkage by a factor $C_{\mathrm{s}}$ set equal to $3 \cdot 0$ (Highways Department, 2006) would overestimate the shrinkage by at least $30 \%$.

From the comparison between the measured ultimate shrinkage strains and the predicted values by Eurocode 2 , it can be seen that at $\mathrm{RH}=75 \%$, the measured ultimate shrinkage strains are on average equal to 1.5 times the predicted values and at $\mathrm{RH}=50 \%$, the measured ultimate shrinkage strains are on average equal to $1 \cdot 1$ times the predicted values. Hence, the predicted ultimate shrinkage strains by Eurocode 2 are also on the low side when compared with the measured results. Nevertheless, the shrinkage model given in Eurocode 2 is in better agreement with the measured ultimate shrinkage strains than the shrinkage model given in BS 5400 .

The measured shrinkage half-times have also been compared with the predicted values by BS 5400, MC90, ACI-209 and Eurocode 2. Again, none of the 

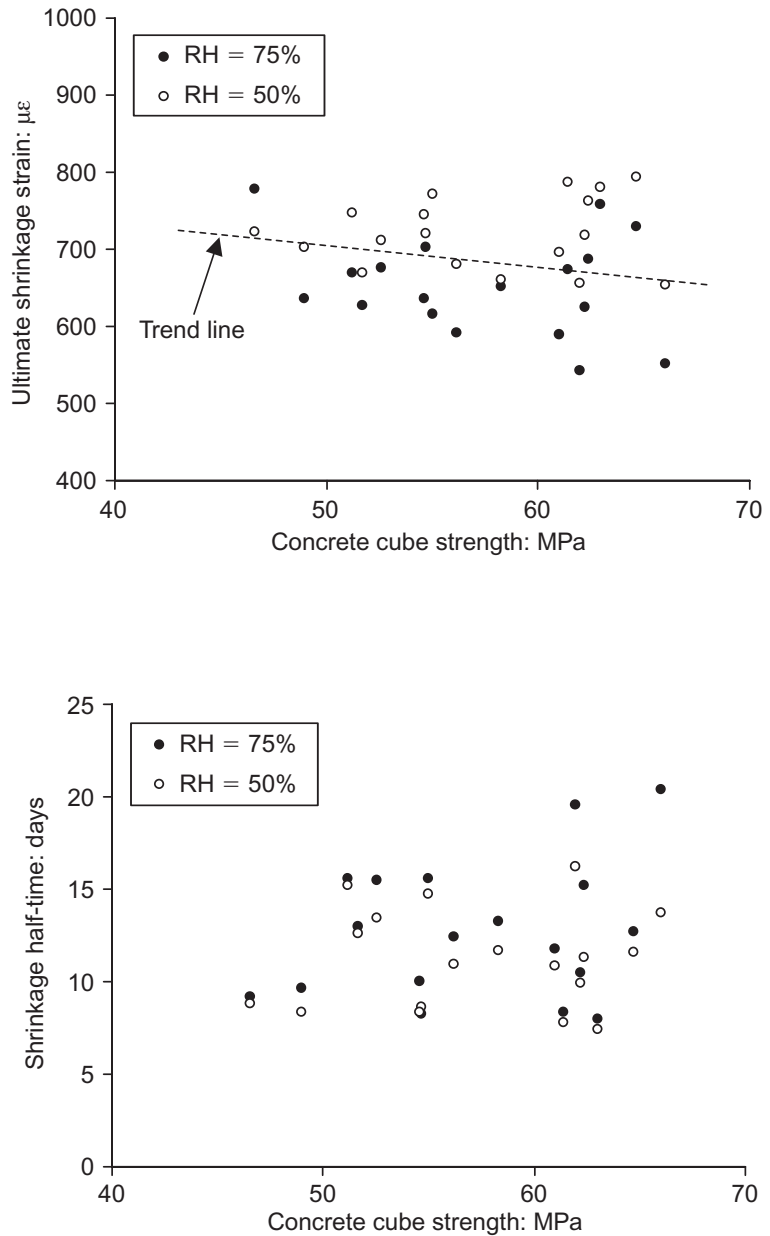

Figure 7. Effects of concrete grade on ultimate shrinkage and shrinkage half-time
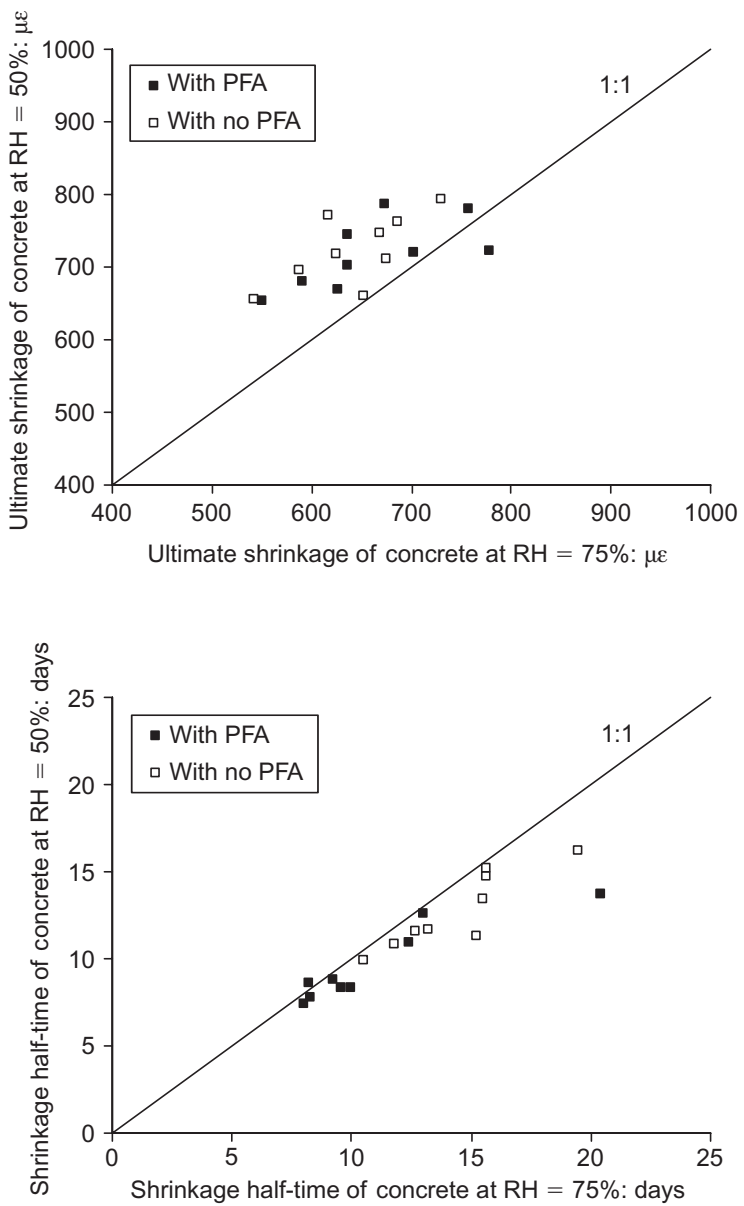

Figure 8. Effects of RH on ultimate shrinkage and shrinkage half-time

Table 5. Comparison of measured ultimate shrinkage strains with code predicted values

\begin{tabular}{|c|c|c|c|c|c|c|}
\hline \multirow[t]{2}{*}{ Mix no. } & \multicolumn{3}{|c|}{ Ultimate shrinkage strain $(\mu \varepsilon)$ at $\mathrm{RH}=75 \%$} & \multicolumn{3}{|c|}{ Ultimate shrinkage strain $(\mu \varepsilon)$ at $\mathrm{RH}=50 \%$} \\
\hline & Measured value & $\begin{array}{l}\text { Predicted by } \\
\text { BS } 5400\end{array}$ & $\begin{array}{l}\text { Predicted by } \\
\text { Eurocode } 2\end{array}$ & Measured value & $\begin{array}{l}\text { Predicted by } \\
\text { BS } 5400\end{array}$ & $\begin{array}{c}\text { Predicted by } \\
\text { Eurocode } 2\end{array}$ \\
\hline 1 & 627 & 264 & 464 & 668 & 401 & 703 \\
\hline 2 & 616 & 294 & 451 & 771 & 447 & 683 \\
\hline 3 & 591 & 239 & 446 & 680 & 364 & 676 \\
\hline 4 & 588 & 264 & 428 & 696 & 401 & 648 \\
\hline 5 & 551 & 220 & 409 & 654 & 334 & 620 \\
\hline 6 & 543 & 248 & 424 & 656 & 376 & 642 \\
\hline 7 & 636 & 303 & 476 & 703 & 460 & 720 \\
\hline 8 & 675 & 347 & 461 & 711 & 527 & 697 \\
\hline 9 & 703 & 270 & 452 & 720 & 410 & 685 \\
\hline 10 & 686 & 303 & 423 & 762 & 460 & 640 \\
\hline 11 & 758 & 253 & 420 & 781 & 385 & 636 \\
\hline 12 & 730 & 275 & 414 & 794 & 418 & 627 \\
\hline 13 & 778 & 347 & 486 & 722 & 527 & 735 \\
\hline 14 & 668 & 385 & 466 & 746 & 585 & 706 \\
\hline 15 & 636 & 314 & 453 & 745 & 477 & 685 \\
\hline 16 & 652 & 341 & 438 & 660 & 518 & 663 \\
\hline 17 & 674 & 283 & 426 & 787 & 431 & 645 \\
\hline 18 & 624 & 311 & 423 & 718 & 472 & 641 \\
\hline
\end{tabular}

Note: When predicting the ultimate shrinkage strains by Eurocode 2, the cylinder strength is assumed to be equal to $0 \cdot 8$ of the cube strength.

Magazine of Concrete Research, 2010, 62, No. 2 
shrinkage models given in these four codes agrees well with the measured results. For the concrete mixes tested, the measured shrinkage half-time ranges within 8 to 20 days. It appears to be dependent on the presence of PFA, paste volume and RH. On the other hand, for an effective thickness of $75 \mathrm{~mm}$, BS 5400, MC-90, ACI-209 and Eurocode 2 yield predicted shrinkage half-times of $38,66,35$ and 26 days, respectively, which are independent of the presence of PFA, paste volume and RH. Although all these predicted shrinkage half-times differ quite significantly from the measured results, comparatively, the shrinkage model in Eurocode 2 is in much better agreement with the measured shrinkage half-times than the shrinkage models in the other codes.

The exact reasons for the large differences between the shrinkage characteristics of the Hong Kong granite aggregate concrete and the theoretical predictions by BS 5400, MC-90, ACI-209 and Eurocode 2 are yet to be investigated. Some suggested possible reasons are

(a) the local granite aggregate is not the same as the aggregates used in the concrete tests from which the formulae given in the various codified shrinkage models were derived

(b) the assumed ambient temperature of $27^{\circ} \mathrm{C}$ for the evaluation of concrete shrinkage in Hong Kong is significantly higher than in most other places

(c) some other factors, such as the addition of PFA, paste volume, effective thickness, ambient temperature and relative humidity, whose effects are still not fully understood, have not been properly accounted for in the existing codified shrinkage models.

Hence, despite years of research, further research is still needed.

Although a large amount of test results have been produced from the present testing programme, it is considered that the data available are not yet sufficient to develop a tailor made shrinkage model for the Hong Kong granite aggregate concrete. To deal with this situation, the strategy of selecting an existing codified shrinkage model that fits best with the test results and modifying the selected shrinkage model to cater for the local materials and local conditions is adopted. Based on the above comparison of the measured results with the respective predicted values by BS 5400, MC-90, ACI-209 and Eurocode 2, the shrinkage model in Eurocode 2 is selected to be the basis for deriving a shrinkage model for Hong Kong.

In Eurocode 2, the ultimate shrinkage $\left(\varepsilon_{\mathrm{sh}}\right)_{\mathrm{u}}$ is evaluated as a product of $k_{\mathrm{h}}, \varepsilon_{\mathrm{s}}\left(f_{\mathrm{cm}}\right)$ and $\beta_{\mathrm{RH}}$, which account for the effects of the effective thickness, concrete grade and $\mathrm{RH}$, respectively. For application in Hong Kong, it is proposed to add two additional multipliers $\beta_{\mathrm{PV}}$ and $C_{\mathrm{s}}$ in the evaluation of the ultimate shrinkage $\left(\varepsilon_{\mathrm{sh}}\right)_{\mathrm{u}}$, as given by the following equation:

$$
\left(\varepsilon_{\mathrm{sh}}\right)_{\mathrm{u}}=C_{\mathrm{s}} \cdot k_{\mathrm{h}} \cdot \varepsilon_{\mathrm{s}}\left(f_{\mathrm{cm}}\right) \cdot \beta_{\mathrm{PV}} \cdot \beta_{\mathrm{RH}}
$$

The multiplier $\beta_{\mathrm{PV}}$ is to account for the effect of the paste volume (or the aggregate content), which has been ignored in Eurocode 2, while the multiplier $C_{\mathrm{s}}$ is to allow for the significantly larger shrinkage of the local concrete under the local conditions.

According to Pickett (1956), the multiplier $\beta_{\mathrm{PV}}$ should be of the form $a(\mathrm{PV})^{\mathrm{b}}$, where $\mathrm{PV}$ is the paste volume expressed as a fraction of the concrete volume, and $a$ and $b$ are coefficients to be determined from the test results. By regression analysis of the data presented in Figure 6 and setting $\beta_{\mathrm{PV}}=1 \cdot 0$ when $\mathrm{PV}=0 \cdot 3$, the following formula for $\beta_{\mathrm{PV}}$ is obtained

$$
\beta_{\mathrm{PV}}=1.52 \times(\mathrm{PV})^{0.35}
$$

However, it is found that whatever numerical value is assigned to the multiplier $C_{\mathrm{s}}$, the Equation 14 would tend to underestimate the shrinkage at $\mathrm{RH}=75 \%$ or overestimate the shrinkage at $\mathrm{RH}=50 \%$. To resolve this problem, the original formula given in Eurocode 2 for $\beta_{\mathrm{RH}}$ has to be modified. By regression analysis of the data presented in Table 4 and setting $\beta_{\mathrm{RH}}$ to have the same value as that given by the original formula when $\mathrm{RH}=0.75$, the modified formula for $\beta_{\mathrm{RH}}$ is derived as

$$
\beta_{\mathrm{RH}}=1.05 \times\left[1-0.35 \times(\mathrm{RH} / 100)^{3}\right]
$$

Lastly, the multiplier $C_{\mathrm{s}}$ has been found by regression analysis of all the data available to be 1.39. After adding the multipliers $\beta_{\mathrm{PV}}$ and $C_{\mathrm{s}}$, and modifying the formula for $\beta_{\mathrm{RH}}$, the predicted ultimate shrinkage strains by Equation 14 agree quite well with the measured results, as illustrated in Figure 9. Comparison of the predicted values by Equation 14 with the measured results shows that within the range of parameters covered, the errors in the predicted ultimate shrinkage strains are generally within $\pm 150 \mu \varepsilon$ and the rootmean-square percentage error is $8 \cdot 3 \%$.

On the other hand, although the measured shrinkage half-times are significantly shorter than the predicted values by Eurocode 2, it is difficult, without further studies, to make any changes to the time function $\beta_{\mathrm{s}}(t)$ in Eurocode 2. Hence, it is proposed to just adopt the formula given in Eurocode 2 for $\beta_{\mathrm{s}}(t)$.

Summarising, the shrinkage model for the Hong Kong granite aggregate concrete is presented as follows. The shrinkage $\varepsilon_{\mathrm{sh}}(t)$ at time $t$ after end of curing is to be evaluated as a product of the ultimate shrinkage $\left(\varepsilon_{\mathrm{sh}}\right)_{\mathrm{u}}$ and the time function $\beta_{\mathrm{s}}(t)$. For the ultimate shrinkage $\left(\varepsilon_{\mathrm{sh}}\right)_{\mathrm{u}}$, the formula is given by Equation 14, in which $C_{\mathrm{s}}=1.39, k_{\mathrm{h}}$ and $\varepsilon_{\mathrm{s}}\left(f_{\mathrm{cm}}\right)$ are the same as those in Eurocode 2, $\beta_{\mathrm{PV}}$ is given by Equation 15 and $\beta_{\mathrm{RH}}$ is given by Equation 16. For the time function $\beta_{\mathrm{s}}(t)$, the same formula in Eurocode 2, that is Equation 13 , should be used.

Magazine of Concrete Research, 2010, 62, No. 2 


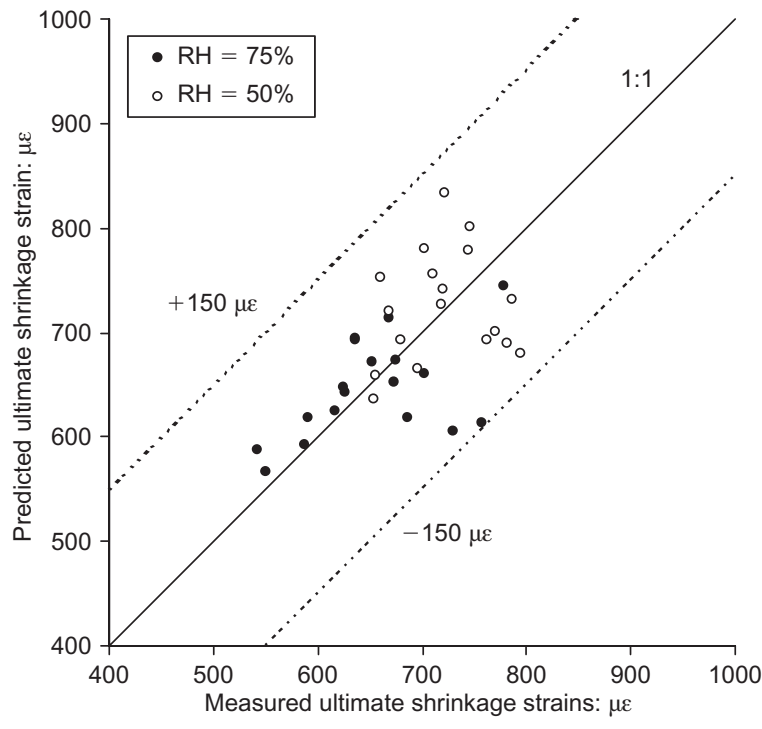

Figure 9. Comparison of predictions by Equation 14 with measured results

\section{Conclusions}

The shrinkage models in BS 5400, MC-90, ACI-209 and Eurocode 2 have been reviewed. It was found that they consider different factors and do not agree with each other. More importantly, none of them would yield accurate predictions of the ultimate shrinkage and shrinkage half-time for the Hong Kong granite aggregate concrete. Hence, researchers in Hong Kong need to carry out their own shrinkage tests to establish their own shrinkage model. However, as a huge amount of tests are required to develop a brand new shrinkage model, a more practical solution is to select among these shrinkage models the one which best fits the shrinkage characteristics of the local concrete under the local conditions and modify the selected shrinkage model based on shrinkage tests to suit Hong Kong applications.

To establish the shrinkage characteristics of the Hong Kong granite aggregate concrete, 18 concrete mixes, of grade 35 to 45 , with and without pulverised fuel ash added, and with paste volume varying from $30 \%$ to $40 \%$, were tested at temperature of $27^{\circ} \mathrm{C}$ and $\mathrm{RH}$ of $75 \%$ and $50 \%$. The results reveal that the ultimate shrinkage decreases as the concrete grade or RH increases but increases as the paste volume increases. On the other hand, the shrinkage half-time is shorter when the concrete contains pulverised fuel ash, the paste volume is larger or the RH is lower. Overall, the ultimate shrinkage is larger and the shrinkage half-time is shorter than predicted by the existing codified shrinkage models. Comparatively, the shrinkage model in Eurocode 2 fits best with the measured results.

Based on the measured results, the shrinkage model in Eurocode 2 is modified by adding two multipliers $\beta_{\mathrm{PV}}$ and $C_{\mathrm{S}}$ into the formula for the ultimate shrinkage, as depicted in Equation 14, and changing the formula for the multiplier $\beta_{\mathrm{RH}}$, as depicted in Equation 16, to become a new shrinkage model for application in Hong Kong. Within the range of parameters covered in the study, this new shrinkage model yields predicted ultimate shrinkage strains, which are generally accurate to an absolute error of $\pm 150 \mu \varepsilon$ or a root-mean-square percentage error of $8 \cdot 3 \%$.

\section{Acknowledgements}

During the first two years of this project, the funding was provided by the Housing Authority Research Fund (Agreement No. CB20030028) while during the later years, the funding was provided by a grant from the Research Grants Council of the Hong Kong Special Administrative Region, China (Project No. HKU 713107E).

\section{References}

ACI (American Concrete Institute) (1997) ACI 209R-92: prediction of creep, shrinkage, and temperature effects in concrete structures. ACI, Detroit, ACI Committee 209.

Alexander M and Mindess S (2005) Chapter 5: Aggregates in hardened concrete: physical and mechanical properties. Aggregates in concrete. Modern Concrete Technology Series. Taylor \& Francis, London, pp. 223-295.

Ayano T and Wittmann FH (2002) Drying, moisture distribution, and shrinkage of cement-based materials. Materials and Structures 35(3); 134-140.

Barr B, Hoseinian SB and Beygi MA (2003) Shrinkage of concrete stored in natural environments. Cement and Concrete Composites 25(1); 19-29.

Bazant ZP, Kim JK, Wittmann FH and Alou F (1987a) Statistical extrapolation of shrinkage data-Part II: Bayesian updating. $A C I$ Materials Journal 84(2); 83-91.

Bazant ZP, Wittmann FH, Kim JK and Alou F (1987b) Statistical extrapolation of shrinkage data-Part I: Regression. ACI Materials Journal 84(1); 20-34.

Bissonnette B, Pierre P and Pigeon M (1999) Influence of key parameters on drying shrinkage of cementitious materials. Cement and Concrete Research 29(10); 1655-1662.

Bloom R and Bentur A (1995) Free and restrained shrinkage of normal and high-strength concretes. ACI Materials Journal 92(2); 211-217.

BSI (British Standards Institution) (1990) Code of practice for design of concrete bridges. BSI, London, BS 5400: Part 4: 1990.

BSI (British Standards Institution) (2004) Eurocode 2: Design of Concrete Structures. Part 1-1: General Rules and Rules for Buildings. BSI, London, BS EN 1992-1-1: 2004.

Campbell-Allen D and Holford JG (1970) Stress and cracking in concrete due to shrinkage. Civil Engineering Transactions 12; 33-39.

CEB (Comité Euro-International du Béton) (1993) CEB-FIP Model Code 1990: Model Code for Concrete Structures. Thomas Telford, London.

Hansen W and Almudaiheem JA (1987) Ultimate drying shrinkage of concrete: influence of major parameters. ACI Materials Journal 84(3); 217-223.

Chai JSV (1980) Investigation into shrinkage and creep of concrete in Hong Kong. Hong Kong Engineer 8(11); 25-30.

China Light and Power (1998) PFA Concrete Studies 1988-1998, Vol. 5, Appendix 5, Deformation behaviour. China Light and Power.

City University of Hong Kong (1995) PFA Concrete Research: Topic 
1, Part 2, Final Report, Shrinkage and Creep. City University of Hong Kong.

Highways Department (2006) Structures Design Manual for Highways and Railways, 3rd edn. Highways Department, Government of the Hong Kong Special Administrative Region, Hong Kong, China.

Kwan AKH, Cai YB and Chan HC (1995) Comparison of granitic and volcanic aggregates for making high strength concrete in Hong Kong. Transactions, Hong Kong Institution of Engineers 2(2); 1-8.

Kwan AKH and Wong HHC (2007) Shrinkage behaviour of concrete in Hong Kong. Materials Science and Technology in Engineering (MaSTEC). Hong Kong Institution of Engineers, Hong Kong, pp. 1-10.

Lee PKK, Kwan AKH and Zheng W (2000) Tensile strength and elastic modulus of typical concrete made in Hong Kong. Transactions, Hong Kong Institution of Engineers 7(2); 35-40.
Neville AM (1995) Chapter 9: elasticity, shrinkage, and creep. In Properties of Concrete. Longman Group, London, 4th edn, pp. $426-443$.

Pickett G (1956) Effect of aggregate on shrinkage of concrete and a hypothesis concerning shrinkage. ACI Journal 52(1); 581-590.

Quirion M and Ballivy G (2000) Laboratory investigation on FabryPerot sensor and conventional extensometers for strain measurement in high performance concrete. Canadian Journal of Civil Engineering 27(5); 1088-1093.

Troxell GE, Raphael JM and Davis RE (1958) Long-time creep and shrinkage tests of plain and reinforced concrete. ASTM Proceedings 58; $1101-1120$.

Discussion contributions on this paper should reach the editor by 1 August 2010 